Elliott Hauser and Joseph Tennis. 2019. Ethics for Contingent Classification: Rorty's Pragmatic Ethics and Postmodern Knowledge Organization. NASKO, Vol. 7. pp. 112-119.

\author{
Elliott Hauser - University of North Carolina at Chapel Hill \\ Joseph Tennis - University of Washington
}

\title{
Ethics for Contingent Classifications: Rorty's Pragmatic Ethics and Postmodern Knowledge Organization
}

\begin{abstract}
There is potential disconnect between a view of classification as historically and culturally contingent and the ethics of KO. For instance, Mai (2011) urges a shift away from the 'modernity' of received classification theory, towards a more pluralistic view that acknowledges the social, political, and historical contingency of classification as a practice. While this is a view shared by many, it is not evident how such an approach can support an ethics which prioritizes a commitment to truth, fairness, democracy, and the common good. A view of such values as merely contingent factors in classification activities would seem to undermine their use as ethical ideals, posing a choice between abandoning modernist tendencies and a workable ethics of KO. An ethics that is consonant with core methodological commitments is critical if we seek to preserve both disciplinary rigor and claim to serve the common good. Rorty's thought is presented as an ethics compatible with a view of classification as contingent.

His suggestion of an ironic ethics is presented and distinguished from cynicism, which is a common misinterpretation of this aspect of his thought. Finally, his ethical principle of solidarity is shown to be broadly compatible with the traditional values of the field of LIS, while approaching it from a philosophical standpoint that doesn't demand or encourage the universalizing tendencies which Mai and others have exhorted us to abandon. In short, this paper attempts to preserve the baby of a workable ethics while discarding the bathwater of universalism in knowledge organization.

\section{Introduction: Postmodern Classification and the Ethics of Pluralism}

A growing number of thinkers have exhorted a commitment to the contingency of classification. Bowker and Star (1999) refocused the field's attention from classification's correctness to its consequences, in the process arguing for a view of classification as culturally contingent. Thinkers from Miksa to Mai have argued against modernist tendencies in classification, and envisioned what it would mean to move to a postmodern classification theory and practice (Miksa 1998; Mai 2011). Melanie Feinberg emphasized that classification is a rhetorical act rather than a kind of science $(2010 ; 2011)$, questioning the centrality of retrieval in the field (2017). Yet, if we embrace contingency in organization, it's unclear how to apply ethics.

A common ethical response to contingency is to call for pluralism. Much of this tradition has been inspired by the work of Patrick Wilson, particularly his later work (Wilson 1983). Wilson's calls for pluralism, what he terms "Pyrrhonian skepticism," have become an ethical touchstone for how to respond to the contingency of classification. Mai, for instance, notes the inherent bias of classification and argues for transparency (Mai 2010)
\end{abstract}


Elliott Hauser and Joseph Tennis. 2019. Ethics for Contingent Classification: Rorty's Pragmatic Ethics and Postmodern Knowledge Organization. NASKO, Vol. 7. pp. 112-119.

and a focus on consequences for marginalized groups in the tradition of Hope Olson (Mai 2016). This is, essentially, the ethical state of the art for those who embrace contingency.

Yet, pluralism doesn't provide the tools needed to say that odious ideas such as racism are wrong, or provide guidance to researchers or practitioners seeking to counter such ideas' negative effects. Wilson's Pyrrhonian skepticism seems outmoded and antiquated in the face of fake news. While calls for transparency and advocacy for marginalized groups are laudable, they don't seem to provide guidance on how to distinguish groups who are marginalized because their beliefs are odious (such as white supremacists or pedophiles). Further, they don't seem to provide any guidance on what to do with factions of traditionally enfranchised groups who claim to be marginalized (such as men's rights advocates or political conservatives). Pluralism is a valuable ethical principle which has done much good for the field. But it cannot be the end of the story if we're to confront the increasingly complex challenges of modern social and political identities.

\section{An Ethical Crossroads}

Thus, it seems that we must either:

1. abandon the commitment to contingency, which has yielded major benefits to the field;

2. adopt an 'anything goes' attitude towards odious ideas and cede the responsibility to counter them to other fields or the public at large; or

3. develop an ethics consistent with a commitment to the contingency of classification that can distinguish beliefs and identities which need protection and elevation from those which we can ethically exclude or actively counteract.

This paper will argue for option 3, because of the benefits of acknowledging social, political, and historical contingency. Option 2 is the default suggested by a blind adherence to calls for pluralism in information studies and the information professions. Yet, as discussed above, it provides none of the guidance needed in the midst of contemporary political and social challenges. Option 1 seems to be an increasingly popular recourse, with some in the field positioning libraries as 'trusted' arbiters of true and false, and a defense against odious ideas. Choosing this option would mean repudiating large swaths of the field's literature. Given evidence and arguments that all classification is rhetorical, contingent, and often marginalizes vulnerable groups (e.g. Tennis 2012; Feinberg 2011; Olson 2001), how can we be sure that we aren't simply replicating our biases when trying to provide a respite from phenomena like fake news with a claim to "truth"?

We assert that we don't have to choose between fruitful methodologies and the ability to distinguish right from wrong. To resolve this apparent dilemma, we suggest looking to others who have confronted it before. In this case, we'll focus on the ethical thought of philosopher Richard Rorty. Rorty's ethics of contingency, irony, and solidarity is a promising approach to this problem that has not received much attention in the context of either $\mathrm{KO}$ or information studies more broadly. 
Elliott Hauser and Joseph Tennis. 2019. Ethics for Contingent Classification: Rorty's Pragmatic Ethics and Postmodern Knowledge Organization. NASKO, Vol. 7. pp. 112-119.

Resuscitating Rorty

In informal discussions with scholars in our field, we have noticed several patterns of thought about the philosophy of Richard Rorty:

- he is usually seen as a skeptical, anti-realist, relativist postmodernist;

- $\quad$ very few are aware of his ethical and political work;

- there seems to be a general preference amongst many for classical pragmatic thought, a sense that Rorty needlessly complicated something that was working just fine.

Thus, the three aims of the following will be to provide a more useful and accurate exposition of Rorty's ethical thought, especially as it might be relevant to information science and the field of knowledge organization; to connect that thought with Rorty's later focus on the ethical and political potentials of Pragmatism; ${ }^{1}$ and finally to argue why Rorty's extension of earlier thought might hold advantages for the field.

Rorty's Ethics of Contingency, Irony, and Solidarity

Rorty's ethics of Contingency, Irony, and Solidarity is explicitly designed to provide ethical guidance within the context of a denial of absolute truth (Rorty 1989). Rorty's version of neopragmatism held that there is no objective reality to moral principles beyond the language we use to express them and the actions we use to enact them. This is the most well-known part of Rorty's earlier work, and a common terminus in knowledge of his thought. Enmeshed in his ethical thought, however, Rorty's account of contingency can be seen as merely a starting point for more important and broadly applicable work.

\section{Contingency}

Contingency is the observation that our knowledge and beliefs are socially and historically conditioned. This applies as well to the stories we tell ourselves about where our knowledge and beliefs fit into their social and historical contexts. For example, the field of cybernetics, which saw the patterns and structures it identified as outside of social and historical context, can be seen in retrospect as enabled by and enmeshed within the Cold War intellectual atmosphere in which it developed (cite, cite). History and sociology are key tools to discover the contingency of past intellectual traditions, and Rorty took the work of Kuhn as particularly important in demonstrating that scientific thought was no less subject to these forces. The historical and social contexts operative in any given present are much more difficult to identify, which can lead to a narrative of progress, of sloughing off of contingency. But Rorty, Kuhn and others insist on the continuity of contingency into the present. Contingency in this sense might be seen to indicate what is commonly understood to be 'postmodernism' or 'relativism,' though those terms are often used pejoratively.

${ }^{1}$ Rorty maintained that the philosophy he espoused was an extension of Pragmatism, and generally resisted the label of 'neopragmatism' placed upon it to distinguish it from classical pragmatism. In this article we will allow Rorty his preferred terminology, and use 'classical pragmatism' when there is need to distinguish his thought from that of Peirce, James, and/or Dewey. In general,we'll capitalize Pragmatism when referring to the philosophical tradition, and leave it uncapitalized when referring to the general attitude. 
While many thinkers and schools might be said to agree with the broad outlines of contingency, Rorty is notable for extricating himself from a defense of the notion and continuing on to search for workable ethical and political principles that might be useful despite it. That is, instead of solely trying to convince others of the contingency of their beliefs, Rorty searched for what we might do and how we might best live in light of the contingency of our beliefs. This is consonant with the tradition of pluralism in information science, and thinkers as diverse as Wilson, Olson, Hjorland, Mai, Tennis, and Feinberg might all be seen as moving beyond debates about contingency to grappling with its consequences, affordances, and potential.

Irony

The next principle, Irony, is Rorty's novel and iconoclastic reaction to contingency. For Rorty, irony is the practice of espousing a full-throated belief in something one knows to be historically and socially contingent, such as human rights, the Good, or the True. Rorty claims that, even though we know our ideals are historically, linguistically, and culturally conditioned, we can and ought to act as though they weren't: "a belief can still regulate action, can still be thought worth dying for, among people who are quite aware that this belief is caused by nothing deeper than contingent historical circumstance" (Rorty 1989, 189). Many of the debates which followed have focused on Rorty's Irony, and this is one of the ideas most clearly associated with him in many readers' minds.

Irony has been attacked from two sides. The realist critique of irony seeks to relitigate the battle over contingency, arguing that irony is actually a concession to the reality of universal ethical concepts. The anti-realist critique of irony balks at the apparent contradiction of holding that something like The Good exists independently of human action, despite an acceptance of the fact that such constructs are, in fact, constructed.

Rorty's sees his justification of this move is inherently Pragmatic: we should do this because, when we do, good things can happen. For an ironist, saying "murder is wrong" in a sincere, strong sense, indicates that there are no conditions under which taking a life is acceptable. ${ }^{2}$ Elevating this from the merely contingent sense in which, historically and socially, we have come to have such principles enables us to move beyond such investigations into the practice of trying to live with one another.

2 Other philosophical approaches such as moral expressivism have developed non-representationalist accounts of moralist language that share some of the characteristics of Rorty's ironism with a less iconoclastic delivery (see especially S. Blackburn 1998; Simon Blackburn 2006). Blackburn's moral expressivism (also oddly termed 'quasi-realism') is primarily motivated by problems in the philosophy of language, however, and concerns the linguistic characteristics of moral language rather than going on to advance ethical principles as Rorty's thought does. Notable extensions of Blackburn's work such as Huw Price's global expressivism maintain this philosophy of language orientation and endeavor, for instance, to show how expressivism is consonant with naturalistic propositions (Price 2010). Although Price's work, in particular, is useful for suggesting that Rorty's thought need not be seen as inconsistent with at least a species of naturalism, neither Price or Blackburn provides much in the way of ethical guidance for practitioners. 
Elliott Hauser and Joseph Tennis. 2019. Ethics for Contingent Classification: Rorty's Pragmatic Ethics and Postmodern Knowledge Organization. NASKO, Vol. 7. pp. 112-119.

But How Shall We Live?

Contingency and irony alone leave us in an untenable place. Like the cynical reverend whose faith in God functions primarily to extract tithes from a congregation, there is considerable space for untenable behavior within a framework that allows for ironic beliefs within a contingent world. This, we stated at the outset, is a common objection to Rorty's ethical thought: if we accept contingency and irony, how do we guard against cynicism? Rorty's ready, but too-often overlooked answer is Solidarity.

\section{Solidarity}

Contingency and irony can be seen as methodological principles, acknowledging the social construction of ideas and espousing a Pragmatic acceptance of some of them even in light of their constructedness, respectively. Solidarity finally introduces an ethical principle into this system of thought, and, importantly, one that is consistent with the first two.

The ethical principle of solidarity is simply that "we try to extend our sense of "we" to people whom we have previously thought of as "they"' (Rorty 1989, 190). By expanding our capacity to recognize others as acceptable examples of what it means to be human, and by holding all humans as deserving of the same respect and dignity, Rorty has resituated humanism as an ethical framework within a postmodern, pragmatist housing.

For those who might be led to exclaim, "That's it? Rorty's ethics amounts to humanism?" it's important to emphasize the deeply conservative nature of Rorty's work. Though often seen as a revolutionary himself due to his willingness to jettison what he saw sa philosophical baggage, Rorty's overall outlook was explicitly that of reformer. He saw the development of liberal democracy, and the personal freedoms and material abundance which it has provided, as an ongoing project which academic inquiry could and rightfully should support. This opened him to criticism from more revolutionary oriented thinkers, especially those who argue that the status quo is inherently discriminatory or even violent to marginalized groups.

Rorty's later thought advanced a pragmatic political philosophy of reform, directly aimed at addressing these criticisms. The following section briefly describes this work, in preparation for relating all of this thought, at last, to the ethics of contingent classification.

\section{Rorty and Reform}

Earlier, we noted that one of Mai's more recent articles highlighted the contributions of Hope Olson, especially in raising the visibility of marginalized groups. Our claim was not that this work was ethically misguided that is obviously not the case. The larger concern is that those who seek out a universalizing ethics are in danger of repeating the mistakes of the past, potentially foreclosing upon this important work.

Univeralisitic tendencies seek to find foundations for our practices, with an implicit corollary that we discard anything which can't be set upon a firm foundation. The problem with deploying this as a strategy to combat racism and hate is that a strongly held universalism of any kind is inherently divisive; that is, presumably, a core function of universalist though: to divide between the just and unjust, right and wrong, justified true belief and nonsense. 
Elliott Hauser and Joseph Tennis. 2019. Ethics for Contingent Classification: Rorty's Pragmatic Ethics and Postmodern Knowledge Organization. NASKO, Vol. 7. pp. 112-119.

Rorty's position is that practices which encourage us to enlarge the sphere of "we" have no need for such tactics. Rather, the quotidian practices of liberal democratic nations, free universities, and the free press themselves embody the ideals we should be striving for. In the context of a debate about academic freedom, Rorty writes, "I take it as a mark of moral and intellectual progress that we are more fully prepared to judge institutions, traditions, and practices by the good they seem to be doing than by the philosophical or theological beliefs invoked in their defense" (Rorty 1998, 3:66). The strength of these institutions depends on consistent, boring, messy efforts to reform them and make them better. And, in that sense, the ethics that KO needs is one that lets it get back to enhancing the visibility of marginalized groups, making classifications more fair, and seeing classification as a democratic force.

\section{Contingency, Irony, and Solidarity in Knowledge Organization}

It's reasonable to expect a reform-oriented ethics of contingent classification to confirm that the field should keep doing at least some of what the field is already doing. In that sense, Rorty's solidarity calls for the kind of focus on marginalized groups that constitutes so much of the field's best (Bowker and Star 1999; Noble 2017; Olson 2001). This work helps to enlarge our understanding of who should be treated as a human beyond, for instance, the median library patron. In addition, work like Bowker and Star's analysis of the apartheid race classification system draws a clear line between classification practices and human misery.

Next, the principle of solidarity can provide the kind of guidance missing from a reliance on the principle of pluralism alone. Solidarity can adjudicate between candidate principles for (ironic) belief by interrogating their impact upon our definition of humanity. Are such beliefs sociopathic or dehumanizing? If so, they are incompatible with our (contingent) ideals, and should be excluded from organization, except as objects of historical, sociological, or anthropological study (such is the fate of "eugenics"). Do such beliefs encourage us to broaden our definition of who counts as an acceptable human, and within that expanded definition benefit all humans? If so, give them visibility and let their rhetorical force engage users of organizational systems. This answer is perhaps overly simplistic, but simplicity may be an important virtue missing from KO's self-conception of what ethics can mean for the field.

\section{What About Our Ideals?}

Some might seek to locate contradictions or inconsistencies within Rorty's framework.

We will briefly address these by applying Rorty's theory to itself; if the resulting framework can be shown to be internally consistent, then it remains a viable metatheoretical perspective. First, it is clear that Rorty's work is historically and socially contingent. It was developed within the anglophone philosophical tradition, which, since the 'linguistic turn' has been investigating many problems of philosophy through an analysis of language. Though the analytic tradition more broadly had sought to reify various formal languages to achieve greater precision and a full account of Logic (often naively held to be a feature of reality), Rorty was part of a revival of American Pragmatism which focused instead on the actual uses of language, rather than attempting to purify language. Thus, Rorty's thought is 
Elliott Hauser and Joseph Tennis. 2019. Ethics for Contingent Classification: Rorty's Pragmatic Ethics and Postmodern Knowledge Organization. NASKO, Vol. 7. pp. 112-119.

eminently contingent: contingent upon the intellectual tradition of American philosophy, the wealth and power of American democracy, and in dialog with the 'culture wars' of the $80 \mathrm{~s}$ and 90 s.

To be faithfully understood, Rorty's thought must be held ironically. The idea of the human, the goal of human happiness, and the justness of liberal democracy are all both presupposed by his thought and yet rendered contingent. Rorty exhorts us to sincerely hold all of these things as ends unto which our journalism, politics, literature, and scholarship should be directed. Yet we must maintain a sense of their contingency simultaneously.

Solidarity is held out as a normative desideratum for which beliefs we should choose to hold ironically, despite their contingency. What licenses choosing Rorty's principle over any other? Wittgenstein, a thinker whose pragmatic sympathies were deeply influential to Rorty, wrote "the difficulty is to realize the groundlessness of our believing" (Wittgenstein 1969, $\S 166)$. Ultimately we do not have and cannot find strongly Universal principles to guide our choice between methods of theory choice (contingency). Yet we do in fact make these choices, or perhaps more accurately we do have some set of beliefs that we hold. And we can and do hold these beliefs even in knowledge of their ultimate groundlessness (irony). What remains, then, is the choice of which set of principles we will allow to adjudicate between these matters. Rorty's solidarity seeks to expand and strengthen the concepts of human dignity. If this is compatible with the mission statements, codes of ethics, and highest ideals of our field, why not select it?

\section{Conclusion}

Rorty's ethics of contingency, irony, and solidarity offers the possibility of taking a stand against odious ideas while preserving intellectual freedom, and does so in a way that is compatible while acknowledging the inherent contingency of human practices, including KO and our study of it. The authors hope that this paper might encourage a deeper engagement with Rorty's thought in KO.

Regardless of whether Rorty's thought is able to perform this role, however, the authors hope to have helped frame the ethical issues facing the field in a way that will encourage further study. Choosing to abandon contingent classification to claim an objective moral high ground would mean disregarding decades of important work. And, more importantly, it ignores the import of that work: that bias is unavoidable, and claims to objectivity in KO are inappropriate for the diversity of beliefs in the populations we serve. Pyrrhonian skepticism wouldn't provide clear ethical guidance and doesn't inherently value contributions that combat marginalization. In this paper we emphasize the importance of a third option, developing an ethics compatible with pluralism. We hope that others will answer this call as well.

\section{References}

Blackburn, S. 1998. Ruling Passions: A Theory of Practical Reasoning. Oxford, UK: Oxford University Press. 
Elliott Hauser and Joseph Tennis. 2019. Ethics for Contingent Classification: Rorty's Pragmatic Ethics and Postmodern Knowledge Organization. NASKO, Vol. 7. pp. 112-119.

Blackburn, S. 2006. Antirealist Expressivism and Quasi-Realism. In The Oxford Handbook of Ethical Theory, edited by David Copp, 146-62. Oxford, UK: Oxford University Press.

Bowker, G.C., and Susan Leigh Star. 1999. Sorting Things Out: Classification and Its Consequences. Cambridge, MA: MIT Press.

Feinberg, M. 2010. Two Kinds of Evidence: How Information Systems Form Rhetorical Arguments. Journal of Documentation 66(4): 491-512.

- 2011. How Information Systems Communicate as Documents: The Concept of Authorial Voice. Journal of Documentation 67(6): 1015-37.

—. 2017. Reading Databases: Slow Information Interactions beyond the Retrieval Paradigm. Journal of Documentation 73(2): 336-56.

Mai, J. 2010. Classification in a Social World: Bias and Trust. Journal of Documentation 66 (5): $627-$ 42.

- 2011. The Modernity of Classification. Journal of Documentation 67 (4): 710-30.

- 2016. Marginalization and Exclusion: Unraveling Systemic Bias in Classification. Knowledge Organization 43(5): 324-30.

Miksa, F.L. 1998. The DDC, the Universe of Knowledge, and the Post-Modern Library. Albany, New York: Forest Press.

Noble, S.U. 2017. Algorithms of Oppression: How Search Engines Reinforce Racism. New York, NY: New York University Press.

Olson, H.A. 2001. The Power to Name: Representation in Library Catalogs. Signs 26(3): 639-68.

Price, H. 2010. Naturalism Without Mirrors. Oxford University Press.

Rorty, R. 1989. Contingency, Irony, and Solidarity. The Clark Lectures. Cambridge University Press. Press.

Tennis, J.T. 2012. The Strange Case of Eugenics: A Subject's Ontogeny in a Long-Lived Classification Scheme and the Question of Collocative Integrity. Journal of the American Society for Information Science and Technology 63(7): 1350-59.

Wilson, P. 1983. Second Hand Knowledge: An Inquiry into Cognitive Authority. Westport, CT: Greenwood Press.

Wittgenstein, L. 1969. On Certainty. Edited by G. E. M. Anscombe and G. H. von Wright. Translated by Denis Paul and G. E. M. Anscombe. New York, NY: Harper Torchbooks. 